\title{
The Impact of Severity of Periodontal Bone Loss and the Levels of Glycated Hemoglobin (HbA1c) on the Periodontal Clinical Parameters of the 2017 World Workshop among Type 2 Diabetic Patients in Saudi Arabia
}

\author{
Mohammed M. A. Abdullah Al-Abdaly ${ }^{*}$, Amer Hassan Alasmari², Ahmed Khalid Asiri², \\ Saeed J. Alqahtani2 , Ahmed Abdulrahman Alzahrani², Joharah Mughaddi Alwadai2, \\ Mohammed Abdullah Thabit ${ }^{2}$
}

\begin{abstract}
${ }^{1}$ Periodontics and Community Dental Sciences Department, College of Dentistry, King Khalid University, Abha, Saudi Arabia ${ }^{2}$ College of Dentistry, King Khalid University, Abha, Saudi Arabia

Email: *malabdaly20@gmail.com
\end{abstract}

How to cite this paper: Al-Abdaly, M.M.A.A., Alasmari, A.H., Asiri, A.K., Alqahtani, S.J., Alzahrani, A.A., Alwadai, J.M. and Thabit, M.A. (2021) The Impact of Severity of Periodontal Bone Loss and the Levels of Glycated Hemoglobin (HbAlc) on the Periodontal Clinical Parameters of the 2017 World Workshop among Type 2 Diabetic Patients in Saudi Arabia. International Journal of Clinical Medicine, 12, 570-591.

https://doi.org/10.4236/ijcm.2021.1212049

Received: December 1, 2021

Accepted: December 20, 2021

Published: December 23, 2021

Copyright $\odot 2021$ by author(s) and Scientific Research Publishing Inc. This work is licensed under the Creative Commons Attribution International License (CC BY 4.0).

http://creativecommons.org/licenses/by/4.0/

\section{Abstract}

Background: Type-2 diabetic patients (uncontrolled levels of glucose blood) usually have periodontal diseases and alveolar bone loss. Objectives: The present study was designed to clarify the impact of severity of periodontal bone loss and the levels of glycated hemoglobin (HbAlc) on the periodontal clinical parameters of the 2017 World Workshop among type 2 diabetic patients in Saudi Arabia (Saudi and non-Saudi). Material and Methods: This study was done on 298 type 2 diabetic patients, selected from the internship clinics, College of Dentistry, King Khalid University, Abha, Saudi Arabia. The selection of patients was dependent on the levels of glycated hemoglobin ( $\mathrm{HbAlc})$, and they were categorized into controlled $(<7 \% \mathrm{HbAlc})$ and uncontrolled type 2 diabetics ( $>7 \% \mathrm{HbA1c}$ ). All patients were divided according to the severity of periodontal bone loss into three groups, group I: mild periodontal bone loss, group II: moderate periodontal bone loss, and group III: severe periodontal bone loss. Clinical evaluation of periodontal diseases was carried out by clinical parameters according to the 2017 World Workshop. All data were collected and analyzed. A p-value of $<0.05$ was considered significant, and of $<0.001$ was considered highly significant. Results: The severity of periodontal bone loss were determined in controlled type 2 diabetics ( $<7 \% \mathrm{HbAlc}$ ) and compared to uncontrolled type 2 diabetics ( $>7 \% \mathrm{HbAlc})$. An increased percentage of patients with severe periodontal bone loss was 
observed in uncontrolled type 2 diabetics (>7\% HbAlc) (42.9\%), as compared to controlled type 2 diabetics ( $<7 \% \mathrm{HbAlc})(30.5 \%)$ without statistically significant $(\mathrm{p}=0.251)$. An increased mean of age, clinical attachment loss $(\mathrm{CAL})$, and percentage of radiographic bone loss (\% RBL) were detected in controlled type 2 diabetics ( $<7 \% \mathrm{HbA} 1 \mathrm{c}$ ), as compared to uncontrolled type 2 diabetics $(>7 \% \mathrm{HbAlc})$. In contrast, we found an increased mean of plaque control record (PCR), gingival bleeding index (GBI), and periodontal pocket depth (PPD) in uncontrolled type 2 diabetics (>7\% HbAlc) more than in controlled type 2 diabetics ( $<7 \% \mathrm{HbA1c}$ ) without statistically significant $(\mathrm{p}>$ 0.05). Moreover, the mean of age, PCR, CAL, \% RBL, and PPD were more in the patients with severe periodontal bone loss, as compared to the patients with mild and moderate periodontal bone. Highly statistically significant differences were recorded $(p<0.001)$. Conclusion: This study demonstrates the role of uncontrolled diabetes as a risk factor for the increase in the severity of periodontal bone loss. Thus, we suggest including the glycated hemoglobin (HbAlc) levels with periodontal parameters in the evaluation of periodontal bone loss among type 2 diabetics.

\section{Keywords}

Glycated Hemoglobin, Periodontal Bone Loss, Saudi Arabia, Type 2 Diabetic

\section{Introduction}

Periodontal diseases are multi-factorial inflammatory diseases of the surrounding dental structures, leading to clinical attachment loss and alveolar bone destruction [1]. The increase in the severity of periodontal bone loss occurs because of irregular inflammatory reactions during some systemic diseases [2].

Type 2 diabetes mellitus (DM) is a chronic systemic disease associated with many complications such as periodontal diseases [3]. The produced inflammatory mediators within the inflamed periodontal structures such as IL-6 and TNF- $\alpha$ interfere with the work of insulin receptors within the systemic circulation, resulting in diminishing sensitivity of insulin [4]. Furthermore, chronic hyperglycemia due to metabolism effect on periodontal tissues health and periodontal diseases severity [5]. Therefore, diabetes mellitus is not the direct cause of periodontal disease, but it is a predisposing factor that assists the local factors and bacterial plaque initiate and developing of periodontal diseases [6].

Periodontal diseases induce alteration of glycemic control in type 2 diabetics and nondiabetics, so periodontitis patients are more susceptible to developing diabetes three times compared to individuals of a healthy periodontium [7].

The destruction effect of type 2 diabetes on alveolar bone occurs due to the reduction of osteoblast formation and an increase of osteoclast formation in inflamed areas (an unbalance of osteoclast and osteoblasts) because of increasing the production of inflammatory cytokines and RANKL/osteoprotegerin (OPG) ratios, enhancing bone resorption [8] [9]. 
Glycosylated hemoglobin ( $\mathrm{HbA}$ ) is formed through a non-enzymatic irreversibly binding between glucose and hemoglobin. Hemoglobin Alc (HbAlc) is the main subpart of $\mathrm{HbA}$ as a beneficial indicator reflecting the glucose concentration in the blood through the last 2 - 3 months [10].

On the other hand, Diabetes mellitus (controlled and uncontrolled) influences approximately 285 million of the world population [11]. The United States has one of the highest percentages of diabetes, with more than $12.3 \%$ (29 million) population $\geq 20$ years of age sufferance from diabetes [12]. Moreover, and according to the Saudi Arabian Ministry of Health reports, Saudi Arabia is one of the top ten countries in the world in the percentages of diabetes, with more than $23.9 \%$ population suffering from diabetes [13].

It is to be noted here that uncontrolled type 2 diabetics $(>7 \% \mathrm{HbAlc}$ ) are more susceptibility to affect and developing of periodontal diseases than controlled $(<7 \% \mathrm{HbA} 1 \mathrm{c})$ as well as controlled type 2 diabetics respond to periodontal therapy, and uncontrolled type 2 diabetics ( $>\mathrm{HbAlc}$ ) are not a good response to periodontal treatment, with complications that may be developing after treatment in the long duration [14].

Previous studies have exhibited the relationship between diabetes and periodontal diseases [15] [16]. But, not considerable papers have been published on the association correlation between the severity of periodontal bone loss and the levels of glycated hemoglobin (HbA1c) among type 2 diabetic patients in Saudi Arabia (Saudi and non-Saudi). Additionally, there have been no studies conducted in the college of dentistry, King Khalid University to assess the impact of glycated hemoglobin levels on the severity of periodontal bone loss among type 2 diabetic patients in Saudi Arabia (Saudi and non-Saudi).regarding the attachment between DM and the periodontal clinical parameters of the 2017 World Workshop. We hypothesized that HbAlc level is associated with the severity of periodontal bone loss. Therefore, the present study was designed to assist the impact of severity of periodontal bone loss and the levels of glycated hemoglobin (HbAlc) on the periodontal clinical parameters of the 2017 World Workshop among type 2 diabetic patients in Saudi Arabia (Saudi and non-Saudi). Consequently, this study will help to develop the health quality and guidelines of type 2 diabetics' medical care to include periodontal checkups as well as will help the physician to design a care plan for type 2 diabetics.

\section{Material and Methods}

\subsection{Design of the Study and Collection of Data}

This cross-sectional study was conducted in the internship clinics, College of Dentistry, King Khalid University, Abha, Saudi Arabia, from December 2020 to May 2021. The study patients included 298 type 2 diabetic patients presenting to the outpatient clinics, College of Dentistry, King Khalid University. Ranged between 35 - 55 years old with a mean age of $43.297 \pm 16.510$ among controlled type 2 diabetics and $42.571 \pm 18.225$ among uncontrolled type 2 diabetics, the 
characteristics of patients were collected, included age, gender, nationality, family history of type 2 diabetes mellitus, and smoking status. The patients were classified as either controlled type 2 diabetics ( $<7 \% \mathrm{HbA} 1 \mathrm{c}$ ) or uncontrolled type 2 diabetics (>7\% HbA1c). Severity periodontal bone loss was determined from the cement-enamel junction (CEJ) to the alveolar crest $(\mathrm{mm})$. The severity of periodontal bone loss was divided into three groups: mild, moderate, and severe. The patients' selection depended on inclusion and exclusion criteria, as well as clinical examination of periodontal diseases and panoramic radiographic explanation to evaluate the periodontal diseases status and severity of the periodontal bone loss.

\subsection{Ethical Statement}

The study proposal was approved by the Institutional Review Board at College of Dentistry, King Khalid University (IRB/KKUCOD/ETH/2020-21/040). All patients were informed of the study's nature, and their consent was obtained. In the present study, all stages were conducted in conformity to the standards of the Helsinki Declaration

\subsection{Inclusion Criteria}

The inclusion criteria were resident patients in Saudi Arabia (Saudi and non-Saudi) older than 30 years who are being diagnosed with type 2 diabetes mellitus since at least two years ago according to the WHO criteria [17]. Every participant in this study should have At least 20 teeth remaining in the mouth.

\subsection{Exclusion Criteria}

All non-residents patients in Saudi Arabia were excluded as well as patients suffering from any systemic disease except type 2 diabetes and patients taking any medication except hypoglycemic drugs. Moreover, the patients who were undergoing periodontal treatment in the last 6 months and the patients who had local risk factors in the oral cavity as well as systemic complications of diabetes were also excluded.

\subsection{Sample Size}

Generally, 95\% of type 2 diabetes patients suffer from periodontal disease, and we expected the same percentage in this study with a $5 \%$ margin of error. The present study was conducted on minimum sample size (298 patients) as required [18].

\subsection{Glycated Hemoglobin (HbA1c) Levels Assessment}

Patients were scanned for excluding the other systemic diseases other than T2DM depending on the patients provided medical reports before starting the study. Glycated hemoglobin (HbA1c) levels were recorded for all type 2 diabetes patients, according to the medical reports. The HbAlc rates are standardized 
according to the National Glycohemoglobin Standardization Program (NGSP) system [19]. When HbAlc is less than or equal $5.7 \%$ (HbAlc $\leq 5.7 \%$ ), the patient is Nondiabetic, and the patient is at risk when HBA1c is less than or equal 6.4 (HBA1c $\leq 6.4)$ but when HBA1c is more than or equal $6.5 \%$ (HBA1c $\geq$ $6.5 \%)$, the patient is diabetic. Consequently, when the HbAlc level in the present study was less than $7 \%(<7 \% \mathrm{HbA} 1 \mathrm{c})$, the patient was considered as controlled type 2 diabetics, and when $\mathrm{HbAlc}$ level was more than $7 \%$ (>7\% HbAlc), the patient was considered as uncontrolled type 2 diabetics [20].

\subsection{Periodontal Examination}

Clinical evaluation of periodontal diseases was included all teeth, but class 3 mobility teeth, third molars, teeth with overhang restorations, and teeth with extensive carious lesions were excluded, where the untreatable teeth were indicted for extraction [21]. A manual periodontal probe (UNC-15, Hu-Friedy, Chicago, IL) was used in the assessment of plaque control record (PCR) [22] and bleeding on probing (BOP) [23], which was evaluated and classified as $<10 \%, 11 \%-30 \%$, and $>30 \%$. In addition, the severity of periodontal disease was evaluated according to the 2017 World Workshop Periodontal diseases and conditions [24] by the assessment of periodontal pocket depth (PPD), clinical attachment level (CAL), which was calculated as $1-2 \mathrm{~mm}$ (mild), $3-4 \mathrm{~mm}$ (moderate) and $\geq 5$ $\mathrm{mm}$ (severe) [25] and furcation involvement (FI). Clinical assessment of PCR, GBI, PPD, and CAL depended on four sites (buccal, mesial, distal, lingual) of all included teeth. Very severe periodontitis: (stage IV) clinical findings were recorded as follow: the number of missing teeth due to periodontal disease ( $>5$ MTDP), trauma from occlusion (TFO), bite collapse (BC), at least 20 remaining teeth (20 RT), and tooth mobility (TM).

\subsection{The Severity of Periodontal Bone Loss}

The severity of alveolar bone in the present study was evaluated according to the American Academy of Periodontology (AAP) as mild ( $<15 \%$ bone loss), moderate (15\% - 33\% bone loss), and severe ( $>33 \%$ bone loss) [26]. Extraoral digital panoramic radiographs (Gendex Orthoralix 9200 DDE, Georgia-USA) were used to obtain the radiographic data, and the MiPACS Dental Enterprise Viewer Program (Medicor Imaging, Charlotte-USA) was applied to measure the radiographic bone level. The panoramic X-ray was screened for the calculation of percentage periodontal bone loss.

The distance between the cementoenamel junction (CEJ) and alveolar bone crest $(\mathrm{ABC})$ and between $\mathrm{CEJ}$ and tooth apex (AP) was measured subtracted by 2 $\mathrm{mm}$ due to the histological distance between the alveolar bone crest to the base of the gingival sulcus was approximately $2 \mathrm{~mm}$, and it was not visible on the radiograph. The distance between the $\mathrm{CEJ}$ and $\mathrm{ABC}$ subtracted by $2 \mathrm{~mm}$ divided by the distance between CEJ and AP subtracted by $2 \mathrm{~mm}$ multiplied by 100 was obtained for percentage radiographic bone loss assessment [27] [28]. 


\subsection{Statistical Analysis}

The findings of this study were collected and analyzed by ANOVA test and T-test to record the mean and standard deviation $( \pm \mathrm{SD})$ of patients' age and the mean and standard deviation (SD) of some clinical and radiographic findings according to $\mathrm{HbAl}$ and severity of radiographic bone loss as well as chi-square to record the percentage of patients in the groups, the smokers' percentage (number of cigarettes smoked per day) and the percentage of some clinical findings according to the severity of periodontal bone loss and the levels of glycated hemoglobin (HbAlc).

By the comparison between the results according to the study groups, the $\mathrm{p}$ values at $\leq 0.05$ were considered statistically significant differences, and it was considered highly statistically significant differences at $<0.001$.

\section{Results}

Three hundred adult male patients were obtained as the sample size in the present study, and all patients completed the study, except two patients who refused to continue in the study. The distributions of patient groups according to the severity of periodontal bone loss and the levels of glycated hemoglobin (HbA1c) are revealed in Table 1 and Figure 1. According to the design of the present study, 256 patients have controlled type 2 diabetics ( $<7 \%$ HbA1c) exhibited the percentage of the affected patients with moderate radiographic bone loss patients was $42.2 \%$ more than the percentage of the affected patients with severe and mild radiographic bone loss patients $30.5 \%, 27.3 \%$, respectively as well as 42 patients were uncontrolled type 2 diabetics $(>7 \% \mathrm{HbAlc}$ ) showed the percentage of the affected patients with severe radiographic bone loss was $42.9 \%$ more than the percentage of the affected patients with mild and moderate radiographic bone loss patients $33.3 \%, 23.8 \%$, respectively, but the differences were not statistically significant $(\mathrm{p}=0.251)$.

Regarding distributions of smokers patients (number of cigarettes smoked per day) according to the severity of the radiographic bone loss, Table 2 and Figure 2 demonstrated that the percentage of the affected patients with severe

Table 1. Distributions of patient groups according to the severity of periodontal bone loss and the levels of glycated hemoglobin (HbA1c).

\begin{tabular}{clccc}
\hline & & \multicolumn{2}{c}{ HbA1c levels } & \multirow{2}{*}{ Total } \\
\cline { 3 - 4 } & & $<7 \%$ HbA1c & $>7 \%$ HbA1c & \\
\hline \multirow{2}{*}{ PBL } & Mild N (\%) & $70(27.3 \%)$ & $14(33.3 \%)$ & $84(28.2 \%)$ \\
& Moderate N (\%) & $108(42.2 \%)$ & $10(23.8 \%)$ & $118(39.6 \%)$ \\
& Severe N (\%) & $78(30.5 \%)$ & $18(42.9 \%)$ & $96(32.2 \%)$ \\
& Total & $256(100 \%)$ & $42(100 \%)$ & $298(100.0 \%)$ \\
\hline \multirow{2}{*}{ Chi-square } & $\chi^{2}$ (p-value) & & $2.767(0.251)$ & \\
\hline
\end{tabular}

N: Number of patients. PBL: Periodontal bone loss. 


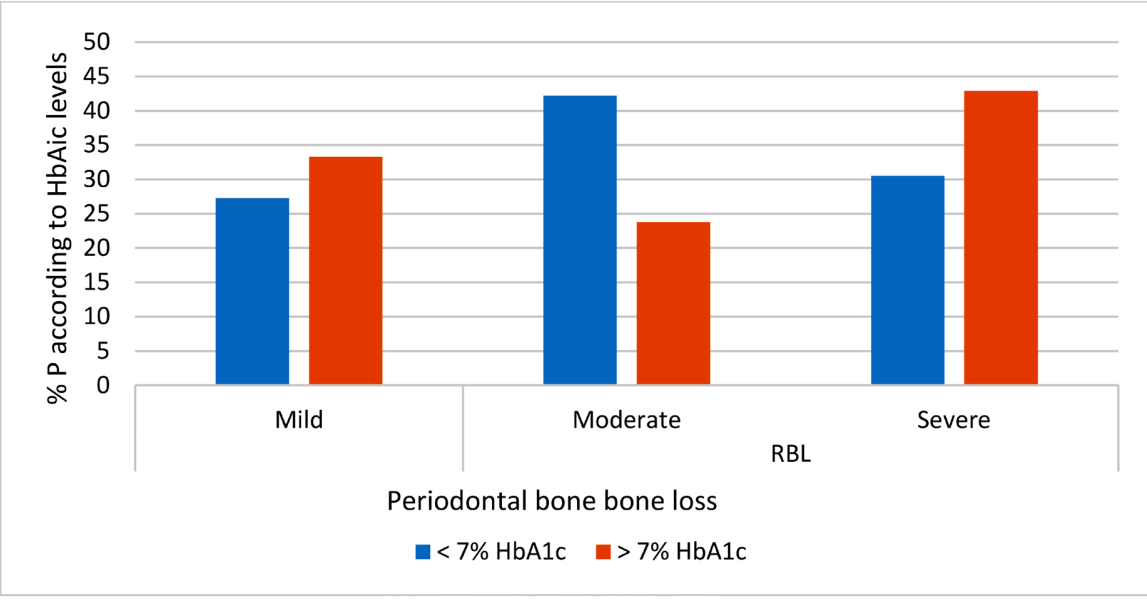

RBL: Radiographic bone loss, HbA1c: Glycated hemoglobin.

Figure 1. Severity of periodontal bone loss according to HbA1c levels.

Table 2. Distributions of smokers' patients (number of cigarettes smoked per day) according to the severity of the radiographic bone loss.

\begin{tabular}{ccccccc}
\hline & & \multicolumn{3}{c}{ Severity of bone loss } & \multicolumn{1}{c}{ Chi-square } \\
\cline { 3 - 7 } & NCs/D & Mild & Moderate & Severe & \multirow{2}{*}{$\chi^{2}$} & p-value \\
& & N (\%) & N (\%) & N (\%) & $\chi^{2}$ & \\
\hline \multirow{2}{*}{ cigarettes Smokers } & $<10$ cig./Day & $30(71.5 \%)$ & $39(66.1 \%)$ & $39(81.3 \%)$ & & \\
& $>10$ cig./Day & $12(28.6 \%)$ & $20(33.9 \%)$ & $9(18.8 \%)$ & & 0.178 \\
& & &
\end{tabular}

NCs/D: Number cigarettes per day. Cig: Cigarettes.

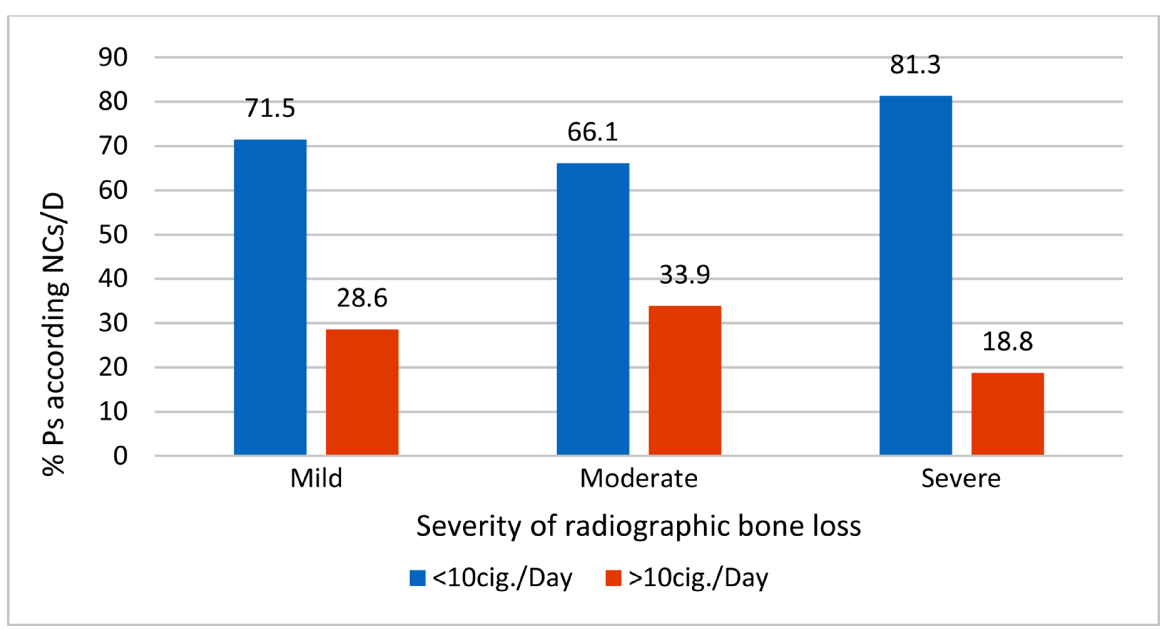

Cig: Cigarettes. Ps: patients.

Figure 2. Smokers according to the severity of radiographic bone loss.

radiographic bone loss was $(81.3 \%)$ more than mild and moderate radiographic bone loss $(71.5 \%, 66.1 \%$, respectively) among cigarettes smokers ( $<10$ cig./day), whereas the percentage of the affected patients with moderate radiographic bone loss was $(33.9 \%)$ more than mild and severe radiographic bone loss $(28.6 \%$, $18.8 \%$, respectively) among cigarettes smokers (>10 cig./day).However, without 
significant differences $(\mathrm{p}=0.178)$.

On the other hand, Table 3 and Figure 3 summarized distribution of smokers patients (number of cigarettes smoked per day) according to the levels of glycated hemoglobin ( $\mathrm{HbAlc}$ ) where the percentage of controlled type 2 diabetics $(<7 \% \mathrm{HbAlc})$ were $73.4 \%$ more than uncontrolled type 2 diabetics $(>7 \%$ $\mathrm{HbA1c}$ ) (66.7\%) among cigarettes smokers ( $<10 \mathrm{cig}$./day) and the percentage of uncontrolled type 2 diabetics (>7\% HbA1c) were (33.3\%) more than controlled type 2 diabetics (<7\% HbAlc) (26.6\%) among cigarettes smokers (>10 cig./day), but the differences were not statistically significant $(\mathrm{p}=0.391)$.

Table 4 and Figure 4 displayed the mean and standard deviation (SD) of patients' age and some clinical and radiographic findings according to glycated hemoglobin (HbA1c) levels of the present study. There was a higher mean of ages (43.297), clinical attachment loss (7.453), and percentage of radiographic bone loss (32.438) among patients with less than 7\% of glycated hemoglobin (< HbAlc) as compared to patients with more than $7 \%$ of glycated hemoglobin (>7\% HbAlc) (42.571, 7.286, and 30.338, respectively). But the patients with more than $7 \%$ of glycated hemoglobin $(>7 \% \mathrm{HbA1c}$ ) presented a higher mean of plaque control record (58.619), gingival bleeding index (44.190), and periodontal pocket depth (4.714) than patients with less than $7 \%$ of glycated hemoglobin $(<\operatorname{HbA1c})(50.345,38.347$ and 4.422., respectively). No statistically significant

Table 3. Smokers patients (number of cigarettes smoked per day) distributions according to the levels of glycated hemoglobin (HbAlc).

\begin{tabular}{cccccc}
\hline & \multicolumn{2}{c}{ HbA1c } & \multirow{2}{*}{ Total } & Chi-square \\
\cline { 3 - 4 } & & $<7 \%$ HbA1c & $>7 \%$ HbA1c & & \\
\hline \multirow{2}{*}{ Smoking } & $<10$ cig. & $188(73.4 \%)$ & $28(66.7 \%)$ & $216(72.5 \%)$ & $\chi^{2}$ (p-value) \\
& $>10$ cig. & $68(26.6 \%)$ & $14(33.3 \%)$ & $82(27.5 \%)$ & $1.878(0.391)$ \\
\hline
\end{tabular}

Cig: Cigarettes.

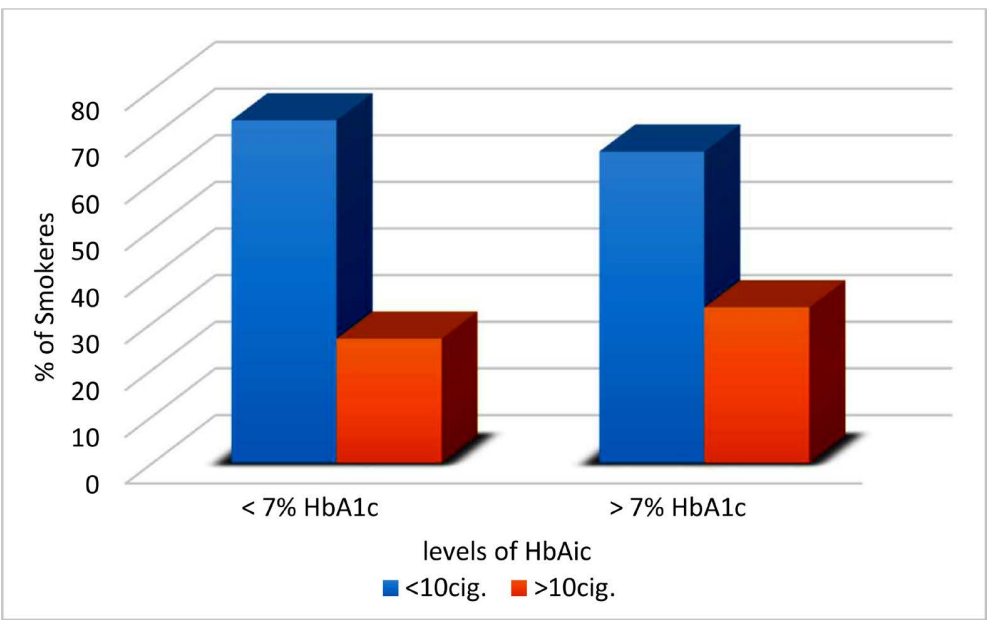

Cig: Cigarettes, HbA1c: Glycated hemoglobin.

Figure 3. Smokers distributions according to levels of HbAlc. 
Table 4. The mean and standard deviation (SD) of patients' age and some clinical and radiographic findings according to HbAlc.

\begin{tabular}{ccccc}
\hline & \multicolumn{2}{c}{ HbAlc } & \multicolumn{2}{c}{ T-test } \\
\cline { 2 - 5 } & $\begin{array}{c}<\% \text { HbA1c } \\
\text { Mean } \pm \text { SD }\end{array}$ & $\begin{array}{c}>7 \% \text { HbA1c } \\
\text { Mean } \pm \text { SD }\end{array}$ & t & p-value \\
\hline AOP & $43.297 \pm 16.510$ & $42.571 \pm 18.225$ & 0.184 & 0.854 \\
PCR & $50.345 \pm 19.158$ & $58.619 \pm 20.011$ & -1.823 & 0.070 \\
GBI & $38.347 \pm 16.205$ & $44.190 \pm 20.361$ & -1.475 & 0.142 \\
CAL & $7.453 \pm 2.872$ & $7.286 \pm 2.667$ & 0.250 & 0.803 \\
\%RBL & $32.438 \pm 20.017$ & $30.338 \pm 13.985$ & 0.462 & 0.645 \\
PPD & $4.422 \pm 1.653$ & $4.714 \pm 1.793$ & -0.742 & 0.459 \\
\hline
\end{tabular}

AOP: Age of patients, PCR: Plaque control record, GBI: Gingival bleeding index, CAL: Clinical attachment loss, \%RBL: \% of radiographic bone loss, PPD: Periodontal pocket depth.

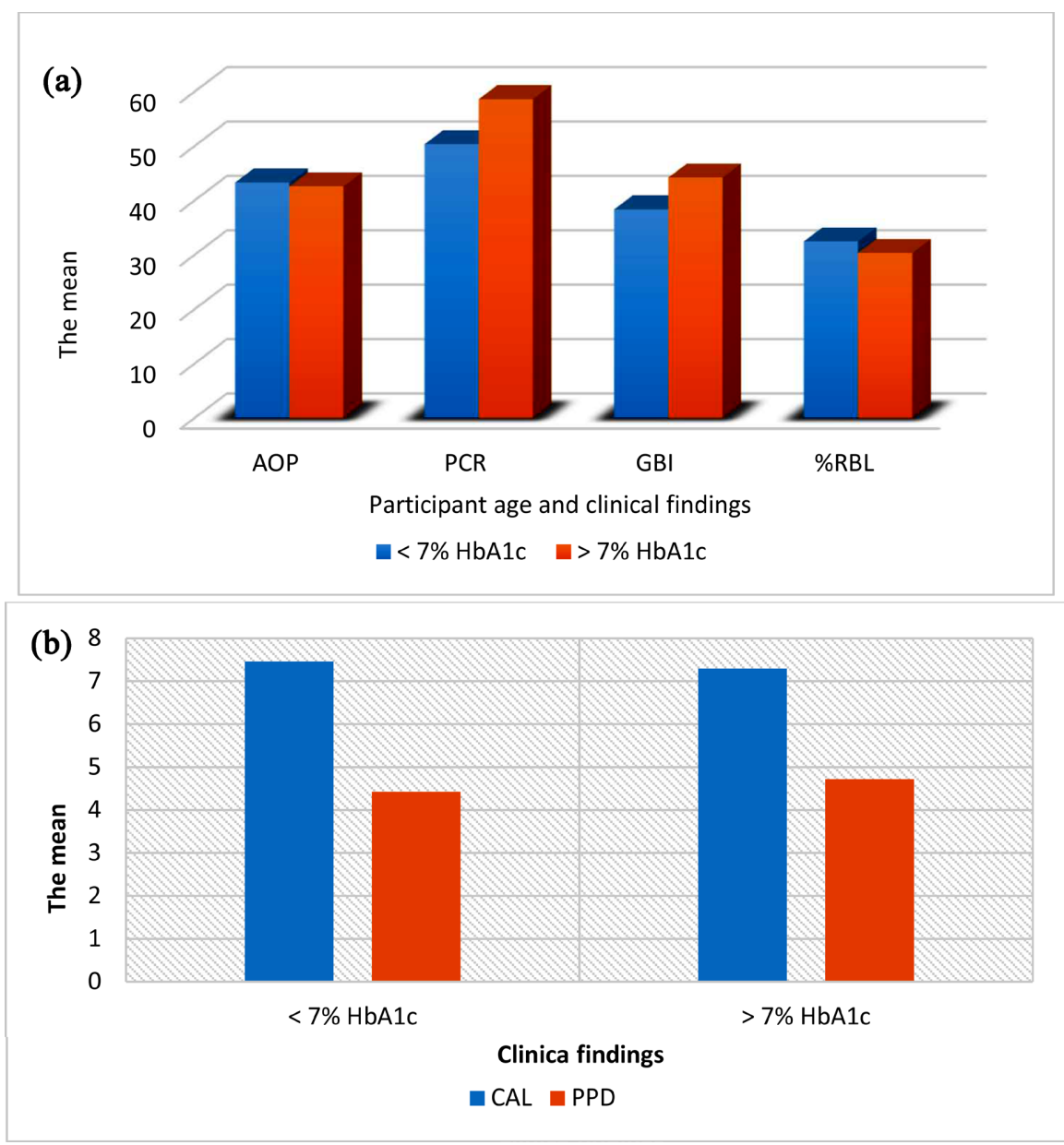

(a) AOP: Age of patients, PCR: Plaque control record, GBI: Gingival bleeding index, \%RBL: \% of radiographic bone loss; (b) CAL: Clinical attachment loss, PPD: Periodontal pocket depth.

Figure 4. (a) The mean of age and clinical and radiographic findings according to HbA1c levels. (b) the mean of CAL and PPD according to HbA1c levels. 
difference is noticed between patients with less than $7 \%$ of glycated hemoglobin $(<\mathrm{HbAlc})$ and patients with more than $7 \%$ of glycated hemoglobin $(>7 \%$ HbA1c) according to the patients' ages, gingival bleeding index, clinical attachment loss, percentage of radiographic bone loss, and periodontal pocket depth $(\mathrm{p}>0.05)$.

Table 5 and Figure 5 demonstrate the distribution of some clinical findings according to glycated hemoglobin (HbAlc) levels. The results showed that the patients with more than $7 \%$ of glycated hemoglobin $(>7 \% \mathrm{HbAlc})$ were higher in percentage than patients with less than $7 \%$ of glycated hemoglobin $(<\mathrm{HbA} 1 \mathrm{c})$ among the patients who were affected with moderate $(10 \%-30 \%)$ gingival bleeding $(28.6 \%)$, the affected patients of severe clinical attachment loss $(>5$ $\mathrm{mm})(90.5 \%)$, the affected patients of 5 missing teeth and more due to periodontal diseases $(42.9 \%)$, the affected patients of bite collapse $(23.8 \%)$, the affected patients of less than 20 remaining teeth (28.6\%), the affected patients of grade I (23.8\%), II (33.3\%) and III (23.8\%)tooth mobility as well as the affected patients of grade IV (19.0\%) furcation involvement.

On the other hand, there are an association between the percentage of patients with less than $7 \%$ of glycated hemoglobin $(<7 \% \mathrm{HbA} 1 \mathrm{c})$ and an increase in the patients who affected with mild (1.6\%) and severe (73.4\%) gingival bleeding, the affected patients of mild (2.3\%) and moderate (10.9\%) clinical attachment loss

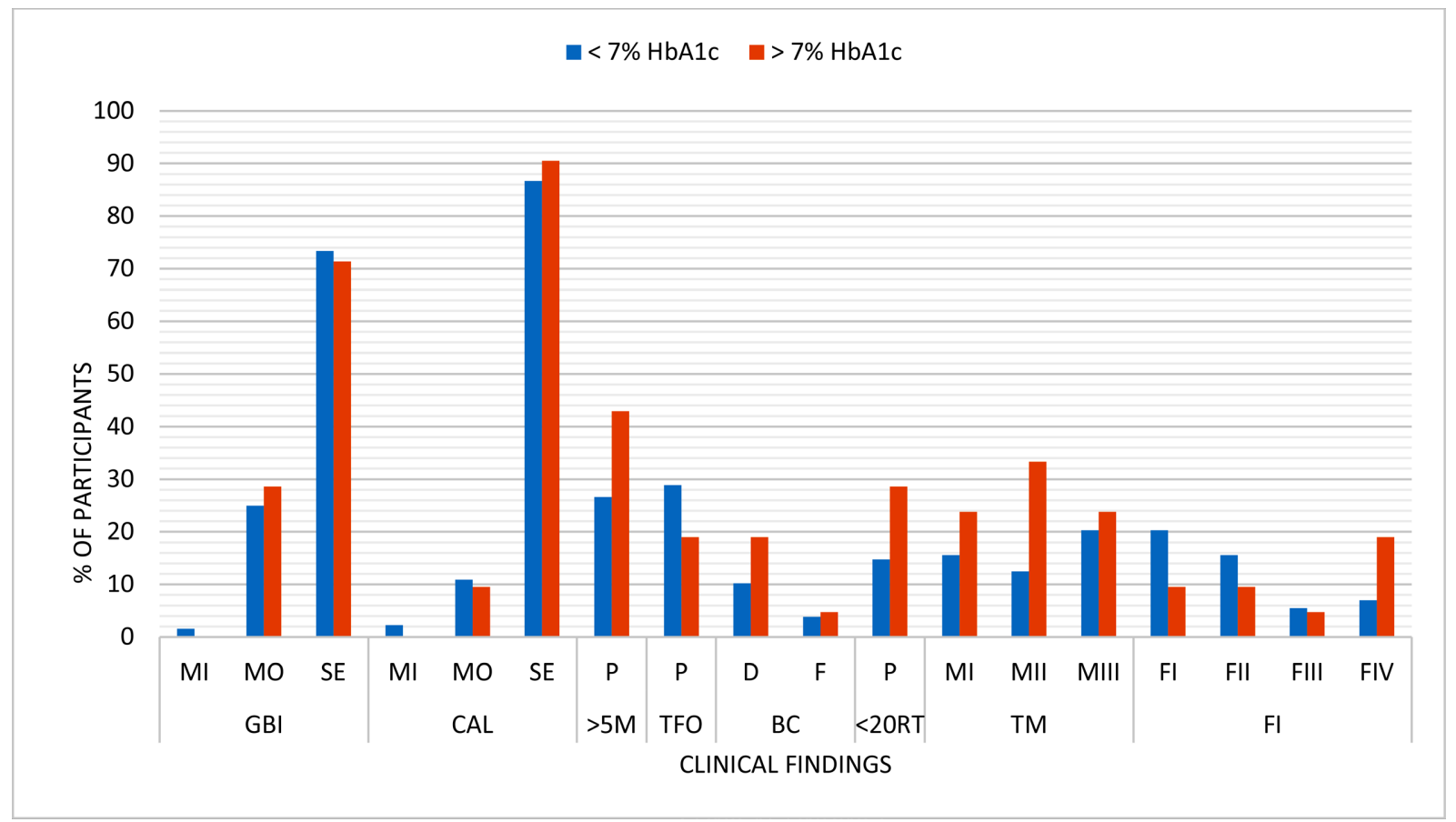

GBI: Gingival bleeding index, CAL: Clinical attachment loss, $>5 \mathrm{M}$ : More than 5 missing teeth due to Perio. Diseases, D: Drifting, F: Flaring, P: Positive, TFO: Present of trauma from occlusion, BC: Bite collapse, $<20$ RT: Less than 20 remaining teeth, TM: Grade of tooth mobility, MI: Grade I tooth mobility, MII: Grade II tooth mobility, MIII: Grade III tooth mobility, FI: Grade of furcation involvement, FI: Grade I furcation involvement, FII: Grade II furcation involvement, FIII: Grade III furcation involvement, FIV: Grade IV furcation involvement.

Figure 5. Distributions of clinical findings according to \% of HbAic participants. 
Table 5. The distribution of some clinical findings according to HbAlc patients.

\begin{tabular}{|c|c|c|c|c|c|}
\hline & & \multicolumn{2}{|c|}{ HbAlc patients } & \multirow{2}{*}{$\begin{array}{l}\text { Total } \\
\text { N (\%) }\end{array}$} & \multirow{2}{*}{$\begin{array}{l}\text { Chi-square } \\
\chi^{2} \text { (p-value) }\end{array}$} \\
\hline & & $\begin{array}{c}<7 \% \text { HbAlc } \\
\mathrm{N}(\%)\end{array}$ & $\begin{array}{c}>7 \% \text { HbAlc } \\
\text { N (\%) }\end{array}$ & & \\
\hline \multirow[t]{3}{*}{ GBI } & $<10 \%(\mathrm{MI})$ & $4(1.6 \%)$ & $0(0.0 \%)$ & $4(1.3 \%)$ & \multirow{3}{*}{$0.705(0.703)$} \\
\hline & $10 \%-30 \%(\mathrm{MO})$ & $64(25.0 \%)$ & $12(28.6 \%)$ & $76(25.5 \%)$ & \\
\hline & $>30 \%$ (SE) & $188(73.4 \%)$ & $30(71.4 \%)$ & $218(73.2 \%)$ & \\
\hline \multirow[t]{3}{*}{ CAL } & $1-2 \mathrm{~mm}(\mathrm{MI})$ & $6(2.3 \%)$ & $0(0.0 \%)$ & $4(1.3 \%)$ & \multirow{3}{*}{$0.975(0.614)$} \\
\hline & 3 - $4 \mathrm{~mm}(\mathrm{MO})$ & $28(10.9 \%)$ & $4(9.5 \%)$ & $76(25.5 \%)$ & \\
\hline & $>5 \mathrm{~mm}(\mathrm{SE})$ & $222(86.7 \%)$ & $38(90.5 \%)$ & $218(73.2 \%)$ & \\
\hline \multirow[t]{2}{*}{$>5$ MTDP } & $\mathrm{N}$ & $188(73.4 \%)$ & $24(57.1 \%)$ & $212(71.1 \%)$ & \multirow{2}{*}{$2.194(0.139)$} \\
\hline & $\mathrm{P}$ & $68(26.6 \%)$ & $18(42.9 \%)$ & $86(28.9 \%)$ & \\
\hline \multirow[t]{2}{*}{ TFO } & $\mathrm{N}$ & $182(71.1 \%)$ & $34(81.0 \%)$ & $216(72.5 \%)$ & \multirow{2}{*}{$0.937(0.333)$} \\
\hline & $\mathrm{P}$ & $74(28.9 \%)$ & $8(19.0 \%)$ & $82(27.5 \%)$ & \\
\hline \multirow[t]{3}{*}{$\mathrm{BC}$} & $\mathrm{N}$ & $220(85.9 \%)$ & $32(76.2 \%)$ & $252(84.6 \%)$ & \multirow{3}{*}{$1.315(0.518)$} \\
\hline & $\mathrm{D}$ & $26(10.2 \%)$ & $8(19.0 \%)$ & $34(11.4 \%)$ & \\
\hline & $\mathrm{F}$ & $10(3.9 \%)$ & $2(4.8 \%)$ & $12(4.0 \%)$ & \\
\hline \multirow[t]{2}{*}{$<20 \mathrm{RT}$} & $\mathrm{N}$ & $218(85.2 \%)$ & $30(71.4 \%)$ & $248(83.2 \%)$ & \multirow{2}{*}{$2.158(0.142)$} \\
\hline & $\mathrm{P}$ & $38(14.8 \%)$ & $12(28.6 \%)$ & $50(16.8 \%)$ & \\
\hline \multirow[t]{4}{*}{ TM } & $\mathrm{N}$ & $132(51.6 \%)$ & $8(19.0 \%)$ & $140(47.0 \%)$ & \multirow{4}{*}{$9.843\left(0.02^{\star}\right)$} \\
\hline & MI & $40(15.6 \%)$ & $10(23.8 \%)$ & $50(16.8 \%)$ & \\
\hline & MII & $32(12.5 \%)$ & $14(33.3 \%)$ & $46(15.4 \%)$ & \\
\hline & MIII & $52(20.3 \%)$ & $10(23.8 \%)$ & $62(20.8 \%)$ & \\
\hline \multirow[t]{5}{*}{ FI } & $\mathrm{N}$ & $132(51.6 \%)$ & $24(57.1 \%)$ & $156(52.3 \%)$ & \multirow{5}{*}{$4.321(0.364)$} \\
\hline & FI & $52(20.3 \%)$ & $4(9.5 \%)$ & $56(18.8 \%)$ & \\
\hline & FII & $40(15.6 \%)$ & $4(9.5 \%)$ & $44(14.8 \%)$ & \\
\hline & FIII & $14(5.5 \%)$ & $2(4.8 \%)$ & $16(5.4 \%)$ & \\
\hline & FIV & $18(7.0 \%)$ & $8(19.0 \%)$ & $26(8.7 \%)$ & \\
\hline
\end{tabular}

GBI: Gingival bleeding index, CAL: Clinical attachment loss, $>5$ MTDP: More than 5 missing teeth due to Perio. Diseases, D: Drifting, F: Flaring, P: Positive, N: Negative, TFO: Present of trauma from occlusion, BC: Bite collapse, $<20 \mathrm{RT}$ : Less than 20 remaining teeth, TM: Grade of tooth mobility, MI: Grade I tooth mobility, MII: Grade II tooth mobility, MIII: Grade III tooth mobility, FI: Grade of furcation involvement, FI: Grade I furcation involvement, FII: Grade II furcation involvement, FIII: Grade III furcation involvement, FIV: Grade IV furcation involvement.

$(>5 \mathrm{~mm}$ ), the percentage of the affected patients of trauma from occlusion $(28.9 \%)$ as well as the affected patients of grade I $(20.3 \%)$, II (15.6\%), and III (5.5\%) furcation involvement (Table 5 and Figure 5). 
According to the Chi-square test, there were no statistically significant differences in the comparison between the percentage of patients with less than $7 \%$ of glycated hemoglobin $(<\mathrm{HbA} 1 \mathrm{c})$ and the percentage of patients with more than $7 \%$ of glycated hemoglobin $(>7 \% \mathrm{HbA1c})$ in the clinical findings within Table 5 $(p>0.05)$ except the grade of tooth mobility, where there was a statistically significant difference in the comparison the percentage of patients with less than $7 \%$ of glycated hemoglobin $(<\mathrm{HbA} 1 \mathrm{c})$ and the percentage of patients with more than $7 \%$ of glycated hemoglobin ( $>7 \% \mathrm{HbA1c}$ ) in grade I, II and III tooth mobility $\left(\mathrm{p}<0.001^{\star}\right)$ (Table 5 and Figure 5$)$.

In the present study, there are associations between severity of radiographic bone loss (mild, moderate, and severe) and the mean of patients' ages, plaque control record, gingival bleeding index, clinical attachment loss, percentage of radiographic bone loss, periodontal pocket depth, where Table 6 and Figure 6 demonstrate a higher mean of ages (53.854) moreover an increase of clinical attachment loss (9.083), percentage of radiographic bone loss (50.290), and periodontal pocket depth (5.229) of affected patients with severe bone loss more than affected patients with moderate and mild bone loss whereas there was a higher mean of plaque control record (54.815) and gingival bleeding index (42.515) among patients with moderate bone loss more than affected patients with severe and mild bone loss. Table 6 results showed statistically significant differences $\left(\mathrm{p}<0.001^{\star}\right)$ except for plaque control record and gingival bleeding index $(\mathrm{p}>0.05)$.

Results of patients' distribution according to clinical findings and severity of radiographic bone loss (mild, moderate, and severe) are demonstrated in Table 7 and Figure 7. In evaluating the severity of radiographic bone loss, the results of the present study revealed that affected patients of severe clinical attachment loss $(>5 \mathrm{~mm})(100.0 \%)$, the affected patients of 5 missing teeth and more due to

Table 6. The mean and standard deviation (SD) of patients' ages and some clinical and radiographic findings according to severity of radiographic bone loss.

\begin{tabular}{|c|c|c|c|c|c|c|c|c|}
\hline & \multicolumn{6}{|c|}{ Bone loss } & \multirow{2}{*}{\multicolumn{2}{|c|}{ ANOVA }} \\
\hline & \multicolumn{2}{|c|}{ Mild } & \multicolumn{2}{|c|}{ Moderate } & \multicolumn{2}{|c|}{ Severe } & & \\
\hline & Mean & SD & Mean & SD & Mean & SD & $\mathbf{F}$ & p-value \\
\hline $\mathrm{AOP}$ & 30.905 & 12.358 & 43.271 & 14.989 & 53.854 & 14.717 & 29.222 & $<0.001^{\star}$ \\
\hline PCR & 45.071 & 20.737 & 54.815 & 19.107 & 53.083 & 17.593 & 3.427 & $0.035^{\star}$ \\
\hline GBI & 34.714 & 14.949 & 42.515 & 16.725 & 38.958 & 18.086 & 2.680 & 0.072 \\
\hline CAL & 5.595 & 2.499 & 7.390 & 2.342 & 9.083 & 2.704 & 21.689 & $<0.001^{\star}$ \\
\hline$\% \mathrm{RBL}$ & 17.845 & 7.654 & 27.554 & 13.918 & 50.290 & 18.222 & 63.992 & $<0.001^{\star}$ \\
\hline PPD & 3.786 & 1.389 & 4.322 & 1.265 & 5.229 & 2.024 & 9.738 & $<0.001^{\star}$ \\
\hline
\end{tabular}

AOP: Age of patients, PCR: Plaque control record, GBI: Gingival bleeding index, CAL: Clinical attachment loss, \%RBL: \% of radiographic bone loss, PPD: Periodontal pocket depth. 


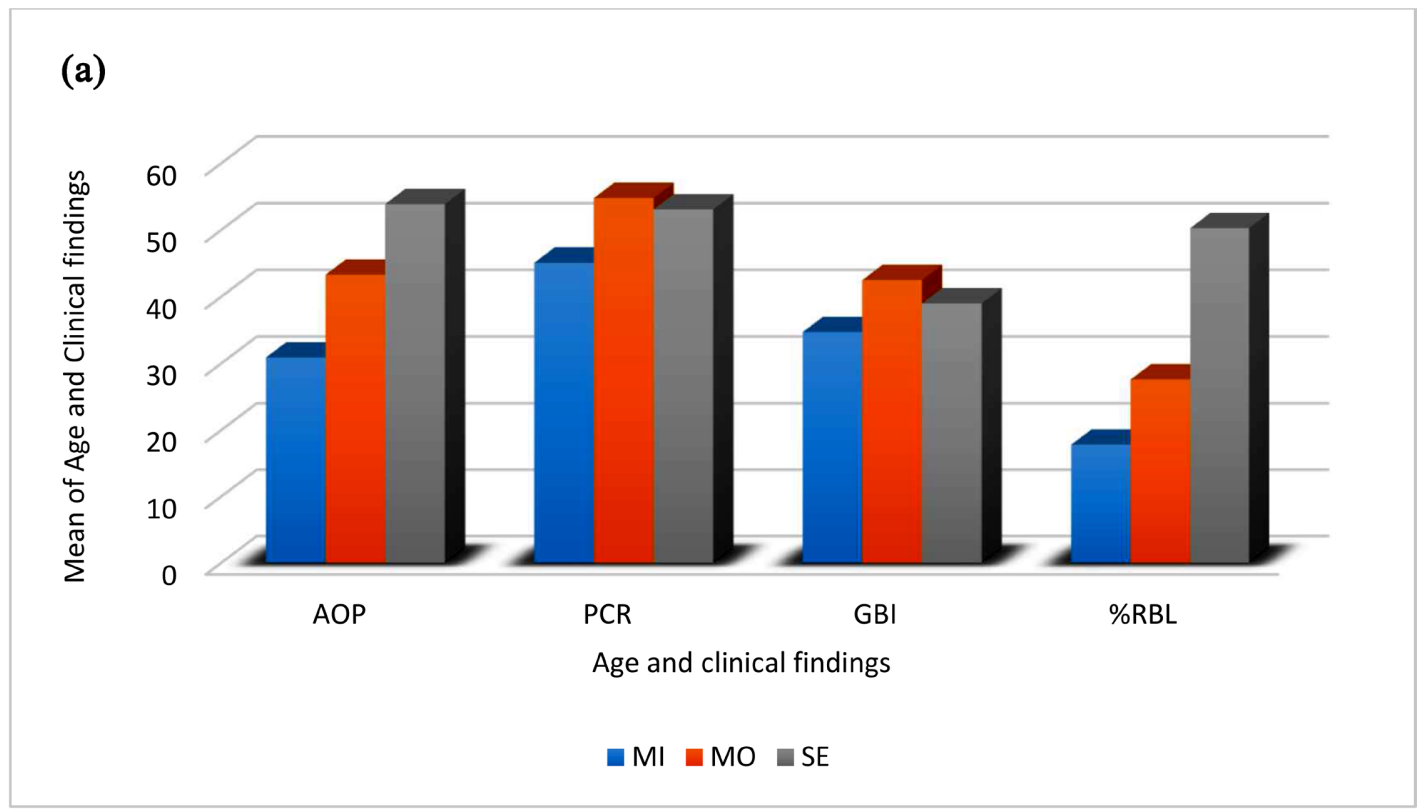

(b)

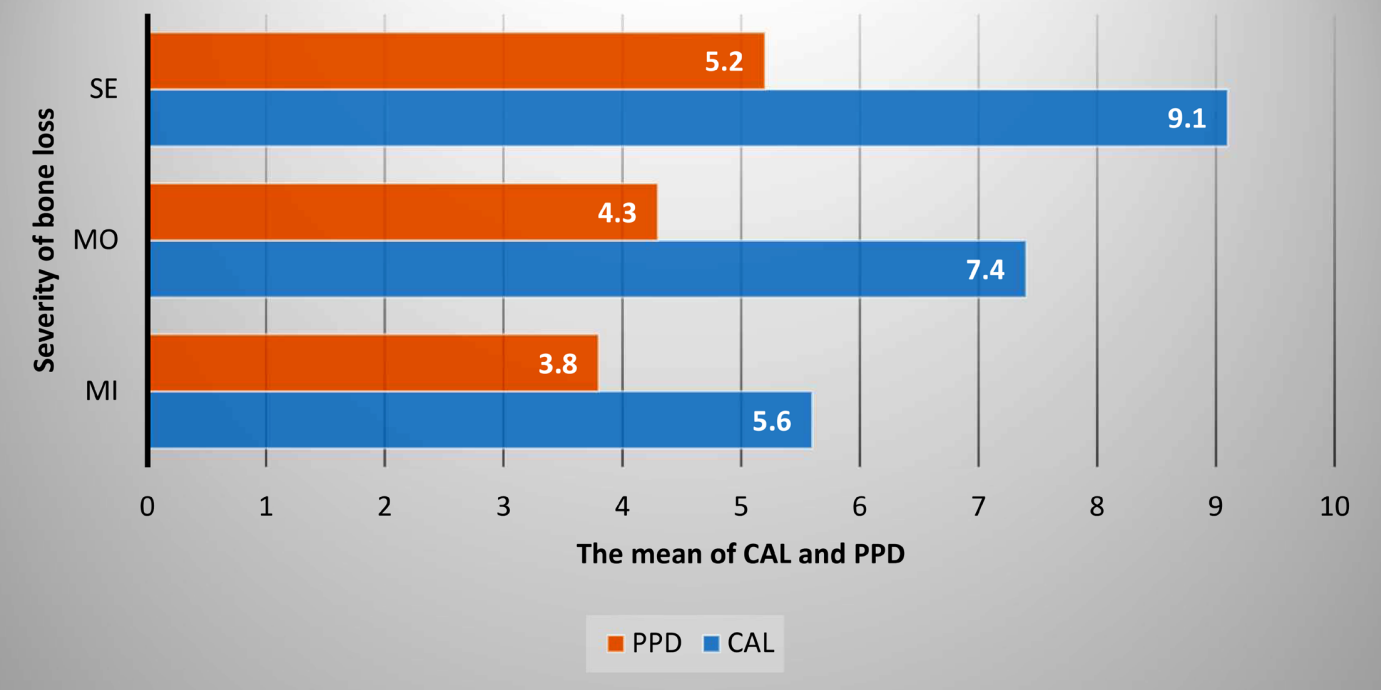

(a) AOP: Age of patients, PCR: Plaque control record, GBI: Gingival bleeding index, \%RBL: \% of radiographic bone loss. (b) CAL: Clinical attachment loss and PPD: Periodontal pocket depth.

Figure 6. (a) Mean of ages correlated to clinical and radiographic findings; (b) Mean of CAL and PPD according to severity of bone loss.

periodontal diseases (52.1\%), the affected patients of trauma from occlusion (35.4\%), the affected patients of bite collapse (27.1), the affected patients of less than 20 remaining teeth $(31.3 \%)$, the affected patients of grade II $(22.9 \%)$ and III (52.1\%) tooth mobility as well as the affected patients of grade II (29.2\%), III (8.3\%), IV (20.8\%) furcation involvement were categorized as having severe radiographic bone loss more than moderate and mild radiographic bone loss.

Moreover, the patients who were affected with mild (10\%) gingival bleeding (2.4\%), the affected patients of mild $(1-2 \mathrm{~mm})(7.1 \%)$ and moderate $(3-4 \mathrm{~mm})$ 
(28.6\%) clinical attachment loss, and the affected patients of grade I tooth mobility $(23.8 \%)$ all were detected as having mild radiographic bone loss more than moderate and severe radiographic bone loss whereas the patients who affected

Table 7. Patients distribution according to clinical findings and severity of radiographic bone loss.

\begin{tabular}{|c|c|c|c|c|c|}
\hline & \multicolumn{3}{|c|}{ Bone loss } & \multirow{2}{*}{$\begin{array}{l}\text { Chi-square } \\
\chi^{2} \text { (p-value) }\end{array}$} \\
\hline & & $\begin{array}{c}\text { Mild } \\
\text { N (\%) }\end{array}$ & $\begin{array}{c}\text { Moderate } \\
\text { N (\%) }\end{array}$ & $\begin{array}{l}\text { Severe } \\
\text { N (\%) }\end{array}$ & \\
\hline \multirow[t]{3}{*}{ GBI } & $<10 \%(\mathrm{MI})$ & $1(2.4 \%)$ & $1(1.7 \%)$ & $0(0.0 \%)$ & $9.356(0.053)$ \\
\hline & $10 \%-30 \%(\mathrm{MO})$ & $14(33.3 \%)$ & $8(13.6 \%)$ & $16(33.3 \%)$ & \\
\hline & $>30 \%$ (SE) & $27(64.3 \%)$ & $50(84.7 \%)$ & $32(66.7 \%)$ & \\
\hline \multirow[t]{3}{*}{ CAL } & $1-2 \mathrm{~mm}(\mathrm{MI})$ & $3(7.1 \%)$ & $0(0.0 \%)$ & $0(0.0 \%)$ & $31.290\left(<0.001^{\star}\right)$ \\
\hline & 3 - 4 mm (MO) & $12(28.6 \%)$ & $4(6.8 \%)$ & $4(6.8 \%)$ & \\
\hline & $>5 \mathrm{~mm}(\mathrm{SE})$ & $27(64.3 \%)$ & $55(93.2 \%)$ & $55(93.2 \%)$ & \\
\hline \multirow[t]{3}{*}{$>5$ MTDP } & $\mathrm{N}$ & $35(83.3 \%)$ & $48(81.4 \%)$ & $23(47.9 \%)$ & $17.997\left(<0.001^{\star}\right)$ \\
\hline & $\mathrm{P}$ & $7(16.7 \%)$ & $11(18.6 \%)$ & $25(52.1 \%)$ & \\
\hline & $\mathrm{N}$ & $34(81.0 \%)$ & $43(72.9 \%)$ & $31(64.6 \%)$ & $3.060(0.217)$ \\
\hline TFO & $\mathrm{P}$ & $8(19.0 \%)$ & $16(27.1 \%)$ & $17(35.4 \%)$ & \\
\hline \multirow[t]{3}{*}{ BC } & $\mathrm{N}$ & $41(97.6 \%)$ & $50(84.7 \%)$ & $35(72.9 \%)$ & $13.179\left(0.01^{\star}\right)$ \\
\hline & $\mathrm{D}$ & $1(2.4 \%)$ & $6(10.2 \%)$ & $10(20.8 \%)$ & \\
\hline & $\mathrm{F}$ & $0(0.0 \%)$ & $3(5.1 \%)$ & $3(6.3 \%)$ & \\
\hline \multirow[t]{2}{*}{$<20 \mathrm{RT}$} & $\mathrm{N}$ & $40(95.2 \%)$ & $51(86.4 \%)$ & $33(68.8 \%)$ & $12.265\left(0.002^{\star}\right)$ \\
\hline & $\mathrm{P}$ & $2(4.8 \%)$ & $8(13.6 \%)$ & $15(31.3 \%)$ & \\
\hline \multirow[t]{4}{*}{ TM } & $\mathrm{N}$ & $29(69.0 \%)$ & $32(54.2 \%)$ & $9(18.8 \%)$ & $59.112\left(<0.001^{*}\right)$ \\
\hline & MI & $10(23.8 \%)$ & $12(20.3 \%)$ & $3(6.3 \%)$ & \\
\hline & MII & $2(4.8 \%)$ & $10(16.9 \%)$ & $11(22.9 \%)$ & \\
\hline & MIII & $1(2.4 \%)$ & $5(8.5 \%)$ & $25(52.1 \%)$ & \\
\hline \multirow[t]{5}{*}{ FI } & $\mathrm{N}$ & $36(85.7 \%)$ & $30(50.8 \%)$ & $12(25.0 \%)$ & $48.480\left(<0.001^{\star}\right)$ \\
\hline & FI & $4(9.5 \%)$ & $16(27.1 \%)$ & $8(16.7 \%)$ & \\
\hline & FII & $1(2.4 \%)$ & 7 (11.9\%) & $14(29.2 \%)$ & \\
\hline & FIII & $1(2.4 \%)$ & $3(5.1 \%)$ & $4(8.3 \%)$ & \\
\hline & FIV & $0(0.0 \%)$ & $3(5.1 \%)$ & $10(20.8 \%)$ & \\
\hline
\end{tabular}

GBI: Gingival bleeding index, CAL: Clinical attachment loss, $>5$ M: More than 5 missing teeth due to Perio. Diseases, D: Drifting, F: Flaring, P: Positive, TFO: Present of trauma from occlusion, BC: Bite collapse, $<20$ RT: Less than 20 remaining teeth, TM: Grade of tooth mobility, MI: Grade I tooth mobility, MII: Grade II tooth mobility, MIII: Grade III tooth mobility, FI: Grade of furcation involvement, FI: Grade I furcation involvement, FII: Grade II furcation involvement, FIII: Grade III furcation involvement, FIV: Grade IV furcation involvement. 


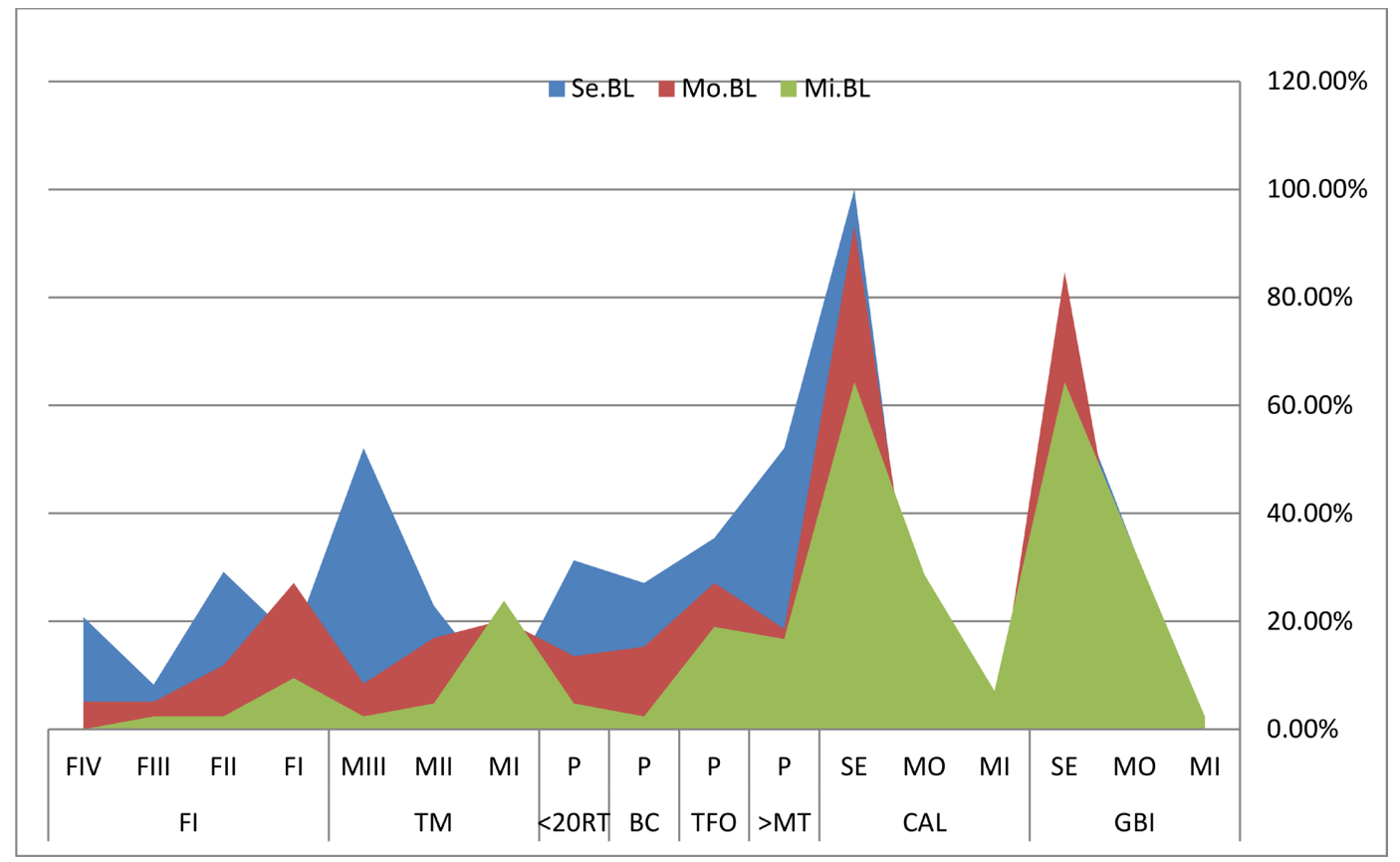

Mi.BL: Mild bone loss, Mo.BL: Moderate bone loss, Se.BL: Severe bone loss, GBI: Gingival bleeding index, CAL: Clinical attachment loss, $>5$ M: More than 5 missing teeth due Perio. Diseases, D: Drifting, F: Flaring, P: Positive, TFO: Present of trauma from occlusion, BC: Bite collapse, <20 RT: Less than 20 remaining teeth, TM: Grade of tooth mobility, MI: Grade I tooth mobility, MII: Grade II tooth mobility, MIII: Grade III tooth mobility, FI: Grade of furcation involvement, FI: Grade I furcation involvement, FII: Grade II furcation involvement, FIII: Grade III furcation involvement, FIV: Grade IV furcation involvement.

Figure 7. Participants distribution according to clinical findings and severity bone loss.

with severe gingival bleeding $(>30)$ revealed moderate $(84.7 \%)$ and severe (66.7\%) radiographic bone loss more than mild (33.3\%) radiographic bone loss.

The statistical analysis showed highly significant differences in the patients' distributions for all clinical and radiographic findings in the present study according to the severity of radiographic bone loss $\left(\mathrm{p}<0.001^{\star}\right)$ except the patients who were affected with mild, moderate, and severe gingival bleeding where there were no statistically significant differences in the patients' distributions $(\mathrm{p}>0.05)$.

\section{Discussion}

The present study assessed the correlation between the severity of periodontal bone loss and the levels of glycated hemoglobin (HbA1c), presence of type 2 diabetes millets, and periodontal diseases in the clinical evaluation of periodontal diseases among type 2 diabetic patients in Saudi Arabia (Saudi and non-Saudi). There was a correlation between severity and progression of periodontal diseases among the individuals with levels of glycated hemoglobin (HbA1c) and between increases of occurrence of periodontal diseases with elevated HbA1c levels [29].

In the present study, there was a passive connection between the patients' ages and HbA1c levels as well as with the severity of periodontal bone loss where the mean of age was 53.854 years among affected patients of severe periodontal bone loss and 42.571 years among uncontrolled type 2 diabetic patients (>HbA1c). 
This study displayed a relationship between the number of cigarettes smoked per day and $\mathrm{HbA1c}$ levels in type 2 diabetic patients where there was a positive relationship of an increase of the number of smoked cigarettes more than ten cigarettes per day with elevated HbAlc. This result was detected in other previous studies [30] [31]. These increases in HbA1c levels may be attributed to impaired glucose metabolism and secretion of insulin during cigarette smoking [32] [33].

In the present study, there was an increase of the periodontal bone loss severity with an increased number of cigarettes smoked per day (>10 cig./day) among type 2 diabetics, but these results were not significant. These findings confirm the results of previous demonstrated that the association between cigarette smoking and severity of periodontal bone loss be evidence of the potential risk factor of cigarette smoking on alveolar bone [34] [35]. Thus, the impact of cigarette smoking on periodontal bone and $\mathrm{HbAlclevels} \mathrm{among} \mathrm{type} 2$ diabetes may be attributed to the inhalation of toxic substances in cigarette smoking where cytotoxic contents of tobacco such as nicotine and cotinine were detected in the gingival crevicular fluid and the saliva [36]. According to previous studies concerning cigarette smoking, there is an association between the severity of periodontal bone loss and the number of cigarettes smoked per day [37] [38]. This finding is in agreement with the results of the present study, which revealed that an increase in periodontal bone loss among cigarettes smokers ( $<10$ cig./day).

Furthermore, the incidence of alveolar bone loss may be considered as the development of periodontal diseases [39]. Similar associations have been detected in the present study. A new study was conducted in 2018 revealed that hyperglycemia has a considerable role in periodontal diseases severity among type 2 diabetics [40]. These results confirmed the results of the present study, which exhibited that generalized severe gingivitis and generalized severe periodontitis are more prevalent in type 2 diabetics (controlled and uncontrolled). These results were not consistent with that of the previous study, which revealed that moderate periodontitis was more among type 2 diabetics [41].

The present study demonstrated that uncontrolled type 2 diabetics had more plaque and severe gingivitis, as evident by the higher scores of GBI and PCR. Similar findings were revealed in another study, which detected higher plaque index and gingival index among uncontrolled type 1 diabetics [42]. Thus, the present study detected that the oral hygiene status was moderate or poor. There were no significant differences in the level of oral hygiene between controlled and uncontrolled type 2 diabetics $(\mathrm{p}=0.070)$, but there were significant differences in the level of oral hygiene between controlled and uncontrolled type 2 diabetics according to the severity of radiographic bone loss $(p=0.035)$. These findings may be due to the little knowledge of the risk for periodontal disease and the awareness of oral health among type 2 diabetic patients in Saudi Arabia (Saudi and non-Saudi).

The results of the present study included comparing the HbAlc levels and periodontal bone loss in patients, which demonstrates the potent link between pe- 
riodontal bone loss and $\mathrm{HbAlc}$ levels. These results are comparable with the Persson study that revealed if there is an increase in the levels of HbAlc; the periodontal bone loss will be severe among uncontrolled type 2 diabetics. [43].

In the present study, the percentage of the affected patients with moderate radiographic bone loss patients was more than the percentage of the affected patients with severe and mild radiographic bone loss patients among controlled type 2 diabetics (<7\% HbAlc) whereas uncontrolled type 2 diabetics $(>7 \%$ $\mathrm{HbA1c}$ ) showed the percentage of the affected patients with severe radiographic bone loss was more than the percentage of the affected patients with mild and moderate radiographic bone loss patients. Thus and according to the present study results, uncontrolled type 2 diabetes has more alveolar bone loss more than controlled type 2 diabetics. These findings agree with Lorentz et al.'s results, which found an increase in clinical and bone attachment loss among type 2 diabetics [44]. Significantly more periodontal bone loss was in uncontrolled type 2 diabetics than controlled [45].

Moreover, this result is in agreement with the epidemiological study of Tsai et al. and Tylor et al., who detected that uncontrolled diabetes type-2 have an increasingly severe clinical attachment loss and alveolar bone loss more than controlled diabetes type- 2 where the results of the current study demonstrated that the mean of clinical attachment loss among uncontrolled diabetes type- 2 more than controlled diabetes type-2 [46] [47]. Therefore, the results of the present study demonstrate that uncontrolled type 2 diabetics have severe periodontal disease more than controlled type 2 diabetics.

Several previous studies confirmed the correlation between hyperglycemia and periodontal diseases are given that periodontitis can cause hyperglycemia and also the impact of hyperglycemia on periodontal tissues integrity [48]. We found a similar intensity association between an increase of periodontal diseases and their severity with the rise of glycated hemoglobin (HbAlc) levels among type 2 diabetics. The patients with uncontrolled type 2 diabetes $(\mathrm{HbAlc} \geq 7)$ in the present study revealed elevated periodontal diseases clinical parameters (mean of PCR, GBI, and PPD) as well as an increase in the affected patients of stage IV periodontitis (severe clinical attachment loss $(>5 \mathrm{~mm}), 5$ missing teeth and more due to periodontal diseases, bite collapse, less than 20 remaining teeth and grade I, II and III tooth mobility) which also was in agreement with the findings of other studies [49] [50].

The present study clarified clinical attachment loss exceeded the mean of 7 $\mathrm{mm}$ among controlled and uncontrolled type 2 diabetics, whereas some studies have revealed lesser clinical attachment loss (less than $4 \mathrm{~mm}$ ) [51]. This study revealed that severe clinical attachment loss, as well as moderate and severe periodontal bone loss, were associated with uncontrolled type 2 diabetics.

\section{Strength and Limitations}

The authors believe that the small sample size of the current study and unequal 
distribution of patients according to the severity of periodontal loss are the main limitations where most of the data were collected from the outpatients' clinics, College of Dentistry, King Khalid University only. Therefore, we suggest expanding the study with an increase in the sample size to cover the other dental centers and colleges of dentistry in Saudi Arabia to determine as accurately the impact of HbAlc levels on the severity of periodontal loss among type 2 diabetic patients in Saudi Arabia (Saudi and non-Saudi). The results of the present study assist in identifying uncontrolled type 2 diabetics with periodontal diseases for the management of uncontrolled type 2 diabetics and periodontal diseases by endocrinologists and periodontists. And as we know that the present study may be from the first studies in the college of dentistry, King Khalid University, which was conducted to assess the correlation between HbAlc levels and severity of periodontal bone loss among type 2 diabetic patients in Saudi Arabia (Saudi and non-Saudi). At the level of the medical and dental practice, these results revealed that the importance of improving the guidelines of screening uncontrolled type 2 diabetics and periodontitis patients in medical primary care centers and dental clinics.

Therefore, in Saudi Arabia, the treatment of periodontal disease of uncontrolled type 2 diabetics is useful in the enhancement of type 2 diabetics' health status due to the negative impact of periodontitis-diabetes interaction on glycemic control of type 2 diabetics. Consequently, the treatment of periodontal diseases should be included in the protocol of type 2 diabetic patients' treatment. Early diagnosis of periodontal diseases among type 2 diabetics and prevention are essential to avoid periodontal tissue destruction. Furthermore, periodontal treatment may be improving $\mathrm{HbAlc}$ levels.

\section{Conclusion}

We conclude according to the results of the current study and the previous studies that demonstrated the association between glycated hemoglobin (HbA1c) levels and severity of periodontal diseases among type 2 diabetic patients in Saudi Arabia (Saudi and non-Saudi). There was an increase in periodontal clinical parameters among uncontrolled type 2diabetics more than controlled type 2 diabetics. We found that the severity of periodontal bone loss increased with decreasing control of type 2 diabetes. Thus, the Risk of aggravating periodontal disease is associated with a rise in glycated hemoglobin (HbAlc) levels among uncontrolled type 2 diabetics. Systematic oral screenings and periodontal therapy are essential to prevent periodontal diseases among type 2 diabetics. We need more periodontal studies to demonstrate the association between $\mathrm{HbAlc}$ levels and severity of periodontal bone loss among type 2 diabetic patients in Saudi Arabia (Saudi and non-Saudi). Emphasize that the awareness and knowledge of dental practitioners and oral public health specialists as well as the primary medical care clinicians that the monitoring of $\mathrm{HbAlc}$ levels and dental plaque with other systemic and local factors are more important to avoid the progres- 
sion of periodontal destruction and other complications in the oral mucosa among type 2 diabetics.

\section{Acknowledgments}

We would like to thank the staff in internship program clinics, College of Dentistry, King Khalid University for helping in the collection of this study data.

\section{Conflicts of Interest}

The authors declare no conflicts of interest regarding the publication of this paper.

\section{References}

[1] Newman, M.G., Takei, H.H. and Carranza. F.A. (2010) Textbook of Clinical Periodontology. 10th Edition, Elsevier, St Louis, 103-104.

[2] Rodrigues, M., Barbirato, D., Luiz, R.R., Scharfstein, J., Salles, G.F. and Feres-Filho, E.J. (2016) Effect of Antihypertensive Therapy with Angiotensin-Converting Enzyme Inhibitors on Chronic Periodontitis: A Case-Control Study. Oral Diseases, 22, 791-796. https://doi.org/10.1111/odi.12551

[3] Iacopino, A.M. (2001) Periodontitis and Diabetes Interrelationships: Role of Inflammation. Annals of Periodontology, 6, 125-137.

https://doi.org/10.1902/annals.2001.6.1.125

[4] Mealey, B.L. and Ocampo, G.L. (2007) Diabetes Mellitus and Periodontal Disease. Periodontology 2000, 44, 127-153. https://doi.org/10.1111/j.1600-0757.2006.00193.x

[5] Jimenez, M., Hu, F.B., Marino, M., Li, Y. and Joshipura, K.J. (2012) Type 2 Diabetes Mellitus and 20 Year Incidence of Periodontitis and Tooth Loss. Diabetes Research and Clinical Practice, 98, 494- 500. https://doi.org/10.1016/j.diabres.2012.09.039

[6] Chang, P.C., Chien, L.Y., Yeo, J.F., Wang, Y.P., Chung, M.C., Chong, L.Y. and Kuo, M.Y., et al. (2013) Progression of Periodontal Destruction and the Roles of Advanced Glycation End Products in Experimental Diabetes. Journal of Periodontology, 84, 379-388. https://doi.org/10.1902/jop.2012.120076

[7] Demmer, A.R.T., Squillaro, P.N., Papapanou, P.N., Rosenbaum, M., Friedewald, W.T., Jacobs Jr., D.R., et al. (2012) Periodontal Infection, Systemic Inflammation, and Insulin Resistance: Results from the Continuous National Health and Nutrition Examination Survey (NHANES) 1999-2004. Diabetes Care, 35, 2235-2242. https://doi.org/10.2337/dc12-0072

[8] Pacios, S., Kang, J., Galicia, J., Gluck, K., Patel, H., Ovaydi-Mandel, A., Petrov, S., Alawi, F. and Graves, D.T. (2012) Diabetes Aggravates Periodontitis by Limiting Repair through Enhanced Inflammation. The FASEB Journal, 26, 1423-1430. https://doi.org/10.1096/fj.11-196279

[9] Wu, Y.Y., Xiao, E. and Graves, D.T. (2015) Diabetes Mellitus Related Bone Metabolism and Periodontal Disease. International Journal of Oral Science, 7, 63-72. https://doi.org/10.1038/ijos.2015.2

[10] Rohlfing, C.L., Little, R.R., Wiedmeyer, H.M., England, J.D., Madsen, R. and Harris, M.I., et al. (2000) Use of GHb(HbA1c) in Screening for Undiagnosed Diabetes in the U.S Population. Diabetes Care, 23, 187-191. https://doi.org/10.2337/diacare.23.2.187

[11] Leite, R.S., Marlow, N.M. and Fernandes, J.K. (2013) Oral Health and Type 2 Di- 
abetes. The American Journal of the Medical Sciences, 345, 271-273.

https://doi.org/10.1097/MAJ.0b013e31828bdedf

[12] Centres for Disease Control and Prevention (2014) National Diabetes Statistics Report: Estimates of Diabetes and Its Burden in the United States. US Department of Health and Human Services, Atlanta.

[13] Aguiree Florencia, Alex Brown, Cho Nam Ho, Dahlquist Gisela, Sheree Dodd, Trisha Dunning, et al. (2013) IDF Diabetes Atlas. 6th Edition, International Diabetes Federation, Basel.

[14] Tsogny-Tsague, N.F., Lontchi-Yimagou, E., Nana, A.R.N., Tankeu, A.T., Katte, J.C., Dehayem, M.Y., Bengondo, C.M. and Sobngwi, E. (2018) Effects of Nonsurgical Periodontal Treatment Glycatedhaemoglobin on Type 2 Diabetes Patients (PARODIA 1 STUDY): A Randomized Controlled Trial in a Sub-Saharan Africa Population. BMC Oral Health, 18, Article No. 28. https://doi.org/10.1186/s12903-018-0479-5

[15] Taylor G.W. (2001) Bidirectional Interrelationships between Diabetes and Periodontal Diseases: An Epidemiologic Perspective. Annals of Periodontology, 6, 99-112. https://doi.org/10.1902/annals.2001.6.1.99

[16] Saito, T., Shimazaki, Y., Kiyohara, Y., Kato, I., Kubo, M. and Iida M, et al. (2004) The Severity of Periodontal Disease Is Associated with the Development of Glucose Intolerance in Non-Diabetics: The Hisayama Study. Journal of Dental Research, 83, 485-490. https://doi.org/10.1177/154405910408300610

[17] WHO Expert Consultation (2004) Appropriate Body- Mass Index for Asian Populations and Its Implications for Policy and Intervention Strategies. Lancet, 363, 157-163. https://doi.org/10.1016/S0140-6736(03)15268-3

[18] Snedecor, G.W. and Cochran, W.G. (1989) Statistical Methods. 8th Edition, Iowa State Press, Ames.

[19] Little, R.R., Rohlfing, C.L. and Sacks, D.B. (2011) National Glycohemoglobin Standardization Program (NGSP) Steering Committee. Status of Hemoglobin A1c Measurement and Goals for Improvement: From Chaos to Order for Improving Diabetes Care. Clinical Chemistry, 27, 205-214. https://doi.org/10.1373/clinchem.2010.148841

[20] Fonseca, V. and Clark, N.G. (2006) Standards of Medical Care Indiabetes-2006. Diabetes Care, 29, 2564-2565. https://doi.org/10.2337/dc06-1150

[21] Costa, F.O., Guimarães, A.N. and Cota, L.O., Pataro, A.L., Segundo, T.K., Cortelli, S.C., et al. (2009) Impact of Different Periodontitis Case Definitions on Periodontal Research. Journal of Oral Science, 51, 199-206. https://doi.org/10.2334/josnusd.51.199

[22] O’Leary, T.J., Drake, R.B. and Naylor, J.E. (1972) The Plaque Control Record. J Periodontol, 43, 38. https://doi.org/10.1902/jop.1972.43.1.38

[23] Ainamo, J. and Bay, I. (1975) Problems and Proposals for Recording Gingivitis and Plaque. International Dental Journal, 25, 229-235.

[24] Caton, J.G., Armitage, G.T., Berglundh, T., Pataro, A.L., Segundo, T.K., Cortelli, S.C., et al. (2018) A New Classification Scheme for Periodontal and Peri-Implant Diseases and Conditions-Introduction and Key Changes from the 1999 Classification. Journal of Periodontology, 89, S1-S8. https://doi.org/10.1002/JPER.18-0157

[25] Newman, M.G., Takei, H.H. and Klokkevold, P.R. (2006) Carranza's Clinical Periodontology. 10th Edition, Elsevier, Noida, 551-553.

[26] AAP Board of Trustees (2015) American Academy of Periodontology Task ForceReport on the Update to the 1999 Classification of Periodontal Diseases and Conditions. Journal of Periodontology, 86, 835-838. 
https://doi.org/10.1902/jop.2015.157001

[27] Cohen, B. (1962) A Study of the Periodontal Epithelium. British Dental Journal, $112,55-68$.

[28] Gargiulo, A.W., Wentz, F.M. and Orban, B. (1961) Dimensions and Relations of the Dento-Gingival Junction in Humans. The Journal of Periodontology, 32, 261-267. https://doi.org/10.1902/jop.1961.32.3.261

[29] Koromantzos, P.A., Makrilakis, K., Dereka, X., Katsilambros, N., Vrotsos, I.A. and Madianos, P.N. (2011) A Randomized, Controlled Trial on the Effect of Non-Surgical Periodontal Therapy in Patients with Type 2 Diabetes. Part I: Effect on Periodontal Status and Glycaemic Control. Journal of Clinical Periodontology, 38, 142-147. https://doi.org/10.1111/j.1600-051X.2010.01652.x

[30] Targher, G., Alberiche, M., Zenere, M.B., Bonadonna R.C., Muggeo, M. and Bonora, E. (1997) Cigarette Smoking and Insulin Resistance in Patients with Noninsulin-Dependent Diabetes Mellitus. Journal of Clinical Endocrinology and Metabolism, 82, 3619-3624. https://doi.org/10.1210/jc.82.11.3619

[31] Eliasson, B., Attvall, S., Taskinen, M.R. and Smith, U. (1994) The Insulin Resistance Syndrome in Smokers Is Related to Smoking Habits. Arteriosclerosis and Thrombosis Journal, 14, 1946-1950. https://doi.org/10.1161/01.ATV.14.12.1946

[32] Piatti, P., Setola, E. and Galluccio, E., Costa, S., Fontana, B., Stuccillo, M., et al. (2014) Smoking Is Associated with Impaired Glucose Regulation and a Decrease in Insulin Sensitivity and the Disposition Index in First-Degree Relatives of Type 2 Diabetes Subjects Independently of the Presence of Metabolic Syndrome. Acta Diabetologica, 51, 793-799. https://doi.org/10.1007/s00592-014-0599-6

[33] Morimoto, A., Tatsumi, Y., Miyamatsu, N., Sonoda, N. and Deura, K. (2014) Association between Smoking and Post-Load Plasma Glucose Levels Using a 75-G Oral Glucose Tolerance Test: The Saku Study. Diabetes Research and Clinical Practice, 106, e38-e40. https://doi.org/10.1016/j.diabres.2014.08.013

[34] de Lima, F.R., Cesar-Neto, J.B., de Lima, D., Kerbauy, W.D. and Nogueira-Filho, G.R. (2008) Smoking Enhances Bone Loss in Anterior Teeth in a Brazilian Population: A Retrospective Cross-Sectional Study. Brazilian Oral Research, 22, 328-333. https://doi.org/10.1590/S1806-83242008000400008

[35] Natto, S., Baljoon, M. and Bergström, J. (2005) Tobacco Smoking and Periodontal Health in a Saudi Arabian Population. Journal of Periodontology, 76, 1919-1926. https://doi.org/10.1902/jop.2005.76.11.1919

[36] Shafagoj, Y., Mohammed, F. and Hadidi, K. (2002) Hubble-Bubble (Water Pipe) Smoking: Levels of Nicotine and Cotinine in Plasma, Saliva and Urine. International Journal of Clinical Pharmacology and Therapeutics, 40, 249-255. https://doi.org/10.5414/CPP40249

[37] Baljoon, M., Natto, S. Abanmy, A. and Bergström, J. (2005) Smoking and Vertical Bone Defects in a Saudi Arabian Population. Oral Health and Preventive Dentistry, 3, 173-182.

[38] Bergström, J. (2004) Influence of Tobacco Smoking on Periodontal Bone Height. Long-Term Observations and a Hypothesis. Journal of Clinical Periodontology, 31, 260-266. https://doi.org/10.1111/j.1600-051X.2004.00475.x

[39] Goodson, J.M., Tanner, A.C., Haffajee, A.D., Sornberger, G.C, and Socransky, S.S. (1982) Patterns of Progression and Regression of Advanced Destructive Periodontal Disease. Journal of Clinical Periodontology, 9, 472-481. https://doi.org/10.1111/j.1600-051X.1982.tb02108.x

[40] Bakshi, D., Kaur, G., Singh, D., Sahota, J., Thakur, A. and Grover. S. (2018) Estima- 
tion of Plasma Levels of Tumor Necrosis Factor-a, Interleukin-4 and 6 in Patients with Chronic Periodontitis and Type II Diabetes Mellitus. The Journal of Contemporary Dental Practice, 19, 166-169. https://doi.org/10.5005/jp-journals-10024-2231

[41] Kumar, A., Pandey, M.K., Singh, A., Mittra, P. and Kumar, P. (2013) Prevalence and Severity of Periodontal Disease in Type 2 Diabetes Mellitus of Bareilly Region (India). International Journal of Medical Science and Public Health, 2, 77-83. https://doi.org/10.5455/ijmsph.2013.2.77-83

[42] Lalla, E., Cheng, B., Lal, S., Kaplan, S., Softness, B. and Greenberg, E., et al. (2007) Diabetes-Related Parameters and Periodontal Conditions in Children. Journal of Periodontal Research, 42, 345-349. https://doi.org/10.1111/j.1600-0765.2006.00955.x

[43] Persson, G.R. (2011) Diabetes and Periodontal Disease: An Update for Health Care Providers. Diabetes Spectrum, 24, 195-198. https://doi.org/10.2337/diaspect.24.4.195

[44] Lorentz, T.C., Cota, L.O., Cortelli, J.R., Vargas, A.M. and Costa, F.O. (2009) Prospective Study of Complier Individuals under Periodontal Maintenance Therapy: Periodontal Parameters, Risk Predictors and the Progression of Periodontitis. Journal of Clinical Periodontology, 36, 58-67. https://doi.org/10.1111/j.1600-051X.2008.01342.x

[45] Tervonen, T., Karjalainen, K., Knuuttila, M. and Huumonen, S. (2000) Alveolar Bone Loss in Type 1 Diabetic Subjects. Journal of Clinical Periodontology, 27, 567-571. https://doi.org/10.1034/j.1600-051x.2000.027008567.x

[46] Tsai, C., Hayes, C. and Taylor, G.W. (2002) Glycemic Control of Type 2 Diabetes and Severe Periodontal Disease in the US Adult Population. Community Dentistry and Oral Epidemiology, 30, 182-192. https://doi.org/10.1034/j.1600-0528.2002.300304.x

[47] Taylor, G.W., Burt, B.A., Becker, M.P., Genco, R.J. and Shlossman, M. (1998) Glycemic Control and Alveolar Bone Loss Progression in Type 2 Diabetes. Annals of Periodontology, 3, 30-39. https://doi.org/10.1902/annals.1998.3.1.30

[48] Mealey, B.L. and Rethman, M.P. (2003) Periodontal Disease and Diabetes Mellitus. Bidirectional Relationship. Dentistry Today, 22, 107-113.

[49] Llambés, F., Silvestre, F.J., Hernández-Mijares, A., Guiha, R. and Caffesse, R. (2005) Effect of Non-Surgical Periodontal Treatment with or without Doxycycline on the Periodontium of Type 1 Diabetic Patients. Journal of Clinical Periodontology, 32, 915-920. https://doi.org/10.1111/j.1600-051X.2005.00736.x

[50] Silvestre, F.J., Miralles, L., Llambes, F., Bautista, D., Solá-Izquierdo, E. and Hernández-Mijares, A. (2009) Type 1 Diabetes Mellitus and Periodontal Disease: Relationship to Different Clinical Variables. Medicina Oral, Patologia Oral, Cirugia Bucal, 14, E175-E179.

[51] Morton, A.A., Williams, R.W. and Watts, T.L. (1995) Initial Study of Periodontal Status in Non-Insulin-Dependent Diabetics in Mauritius. Journal of Dentistry, 23, 343-345. https://doi.org/10.1016/0300-5712(94)00001-V 